\title{
Thermal Fatigue Life Prediction of Ventilation Air Methane Oxidation Bed
}

\author{
Y. Q. Liu, ${ }^{1}$ Q. H. Shang, D. H. Zhang, Y. X. Wang, and T. T. Sun \\ School of Traffic and Vehicle Engineering, Shandong University of Technology, Zibo, China \\ ${ }^{1}$ liuyq65@163.com
}

Thermal flow-reversal oxidation is the main technology that can effectively reduce emissions of ventilation air methane. As the core component of coal mine ventilation oxidation devices, honeycomb ceramic oxidation beds play a decisive role in the functionality of these devices. The thermal fatigue properties of mullite ceramic - which is commonly used in oxidation beds - was tested in the present research. Then, the service life of the oxidation bed was predicted according to the intensity attenuation law and the thermal fatigue experimental data. The results of the fatigue experiment indicated that in general, the bending strength of mullite ceramics decreases as thermal shocks increase. At higher temperature differences, the bending strength decreased at greater rates. At the temperature differences between 600 and $800^{\circ} \mathrm{C}$, the bending strength initially declined. Then, after reaching a certain value, it remained unchanged for a while before declining again. The results of the equation that was developed from intensity attenuation theory and the thermal fatigue experimental data indicate that the thermal fatigue life of an oxidation bed is about 1-8 months. The predicted result is consistent with actual working conditions.

Keywords: oxidation bed, mullite ceramics, thermal fatigue performance, fatigue life.

Introduction. The gaseous mixture that is emitted by coal mine ventilation systems is known as ventilation air methane (VAM). In VAM, the methane content is generally less than $1 \%$. VAM is usually discharged into the atmosphere directly, and little is recycled. Methane has a very strong greenhouse effect. Its greenhouse effect is 21 times greater than $\mathrm{CO} 2$. In addition, it causes 7 times more destruction to the ozone layer than $\mathrm{CO}_{2}$ [1-4].

The thermal flow-reversal reactor is a good candidate to utilize the low methane concentrations contained in VAM, and has been commercially used in Australia and China $[5,6]$. As the core component of coal mine ventilation oxidation devices, honeycomb ceramic oxidation beds play a decisive role in the functionality of devices. The performance of honeycomb ceramic oxidation beds determines the performance of the entire device. It is therefore an important undertaking to create a method of predicting the lifespan of the honeycomb ceramic. While most of the research has been focused on regenerative oxidation beds' heat transfer performance [7-9], few scholars have studied the service life of a regenerative oxidation bed. To meet this need, thermal fatigue life of regenerative oxidation bed is predicted in this paper.

\section{The Thermal Fatigue Test.}

1.1. Materials. Mullite ceramic was selected for use in the thermal fatigue experiments. The specimens of the mullite ceramic are shown in Fig. 1. The specimen model was pressed on a 30-ton hydraulic machine (the molding pressure is $25 \mathrm{MPa}$ ). The forming specimens were sintered in an electric furnace at $1300^{\circ} \mathrm{C}$. The basic physical parameters of the specimens are shown in Table 1.

1.2. Methods. The specimens were first tested for fatigue by thermal shock. The specimens' bending strength was subsequently tested in order to obtain the representative thermal fatigue properties of the materials. In the thermal shock process, the specimens were placed into an electric furnace, which were heated to the preset temperature and kept at that temperature for 20 minutes. Then, the specimens were removed from the furnace and allowed to cool in the air to room temperature. The above steps were repeated according to 
$\mathrm{T}$ a b 1 e 1

\section{Basic Physical Parameters}

\begin{tabular}{|c|c|c|c|c||}
\hline $\begin{array}{c}\text { Density } \\
\left(\mathrm{g} / \mathrm{cm}^{3}\right)\end{array}$ & $\begin{array}{c}\text { Elastic modulus } \\
(\mathrm{GPa})\end{array}$ & $\begin{array}{c}\text { Poisson's } \\
\text { ratio }\end{array}$ & $\begin{array}{c}\text { Flexural strength } \\
(\mathrm{MPa})\end{array}$ & $\begin{array}{c}\text { Fracture toughness } \\
\left(\mathrm{MPa} \cdot \mathrm{m}^{1 / 2}\right)\end{array}$ \\
\hline 1.83 & 26.72 & 0.17 & 25.34 & 0.62 \\
\hline
\end{tabular}

T a b 1 e 2

\section{Scheme of Thermal Shock}

\begin{tabular}{|c|c|c|}
\hline Temperature difference $\left(\Delta T,{ }^{\circ} \mathrm{C}\right)$ & Number of thermal shocks & Number of specimens \\
\hline 200 & $5,10,20,30$, & $8 \times 25$ \\
\hline 300 & $40,50,60,70$ & $8 \times 25$ \\
\cline { 1 - 1 } & & $\ldots$ \\
\hline 700 & & $8 \times 25$ \\
\hline \multirow{2n}{*}{800} & & $8 \times 25$ \\
\hline
\end{tabular}

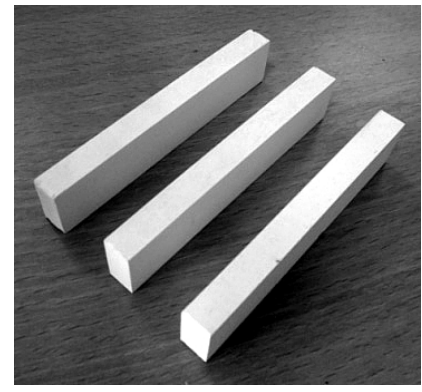

a

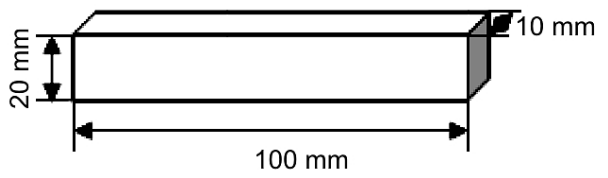

b

Fig. 1. Mullite specimens (a) and specimen dimensions (b).

the thermal shock scheme. Considering the oxidation bed's working temperature, the thermal shock temperatures were selected in the range of 0 to $1000^{\circ} \mathrm{C}$. The full thermal shock scheme is shown in Table 2. According to GB3001-82, the bending strength of the shocked specimens were tested on an universal testing machine (CMT5305), which was produced by the SANS company. The loading rate was set at $0.5 \mathrm{~mm} / \mathrm{min}$. The residual strength was calculated by the following formula [10]:

$$
\sigma_{f}=\frac{3 P L}{2 B W^{2}}
$$

where $\sigma_{f}$ is the residual bending strength, $\mathrm{Pa}, P$ is the fracture load, $\mathrm{N}, L$ is the roller span, $\mathrm{m}, B$ is the width of the specimen, $\mathrm{m}$, and $W$ is the height of the specimen, $\mathrm{m}$.

Because of porosity, impurities, and cracks in the specimens, it was anticipated that the measured strength value will have a lot of dispersions. To guarantee the reliability of the experimental data, 25 specimens in each group in the experiment were used.

1.3. Results and Discussion. Figure 2 shows the thermal fatigue curves for the varied temperature differencees. The curves show that for every temperature difference, the bending strength declined as the thermal shocks increased. At the same time, the attenuation laws of bending strength for different temperature differences were different. At temperature 


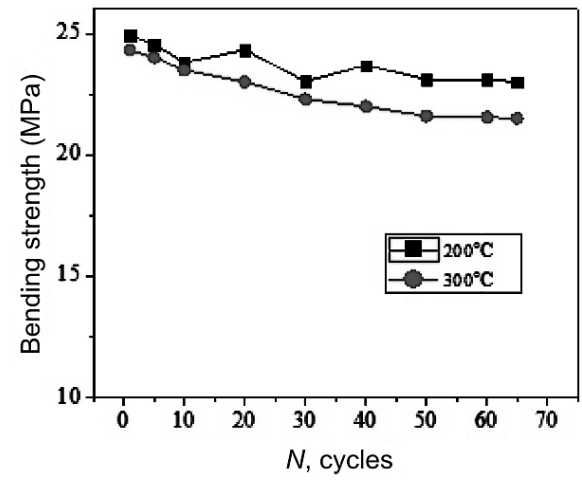

a

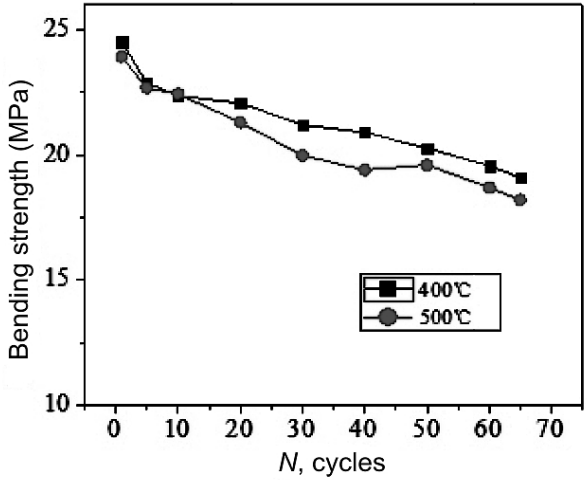

b

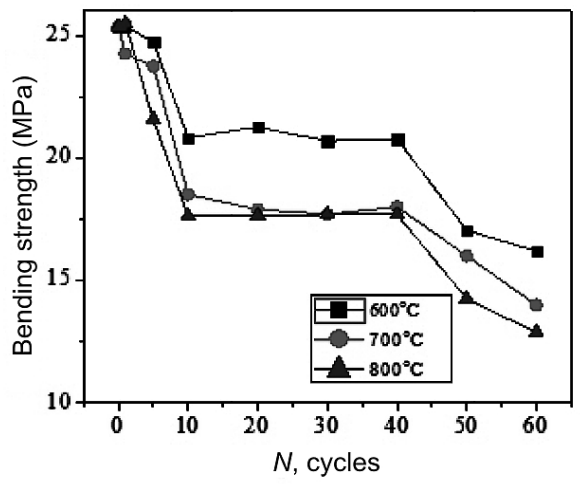

$\mathrm{c}$

Fig. 2. Thermal fatigue test curve under different temperature differences: (a) at 200 and $300^{\circ} \mathrm{C}$; (b) at 400 and $500^{\circ} \mathrm{C}$; (c) at 600,700 , and $800^{\circ} \mathrm{C}$.

differences of 200 and $300^{\circ} \mathrm{C}$, the bending strength declined slowly with the increase of the thermal shocks. For these two specimens, the largest drops of the bending strength at the temperature differencees were 1.4 and $2.1 \mathrm{MPa}$, respectively. At temperature differencees of 400 and $500^{\circ} \mathrm{C}$, the bending strength declined more quickly. The largest drops in the bending strength were 5.8 and $7.6 \mathrm{MPa}$, respectively. At temperature differencees of 600 , 700 , and $800^{\circ} \mathrm{C}$, the attenuation law of bending strength was significantly different from the previous specimens. With the increase in thermal shocks, the bending strength declined first. After reaching a certain value it remained unchanged for a while before declining again. As the specimens were shocked for the first 10 times, the high thermal stress caused cracks, which in turn caused the bending strength to drop sharply. In the range of 10-40 shocks, the bending strength remained unchanged because there was no new crack generation, and the existing micro crack continued to develop in depth and length. A schematic diagram of the crack's extension is shown in Fig. 3. After 40 shocks, the strength continued to decline.

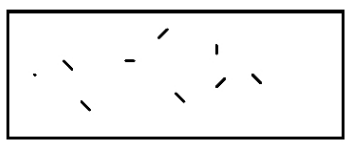

a

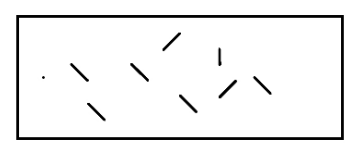

b

Fig. 3. Schematic diagram: (a) 0-10 shocks; (b) 10-40 shocks. 


\section{The Fatigue Life Prediction of Regenerative Oxidation Bed.}

2.1. The Intensity Attenuation Theory. The exact damage process is difficult to determine because of its complexity. It includes a number of factors, such as the development and accumulation of micro cracks under thermal stress, grain boundary phase softening, and hole size increases caused by creep or oxidation at high temperature. Still, no matter what the damage mechanism is or how the damage process develops, the macroeffect is that the residual strength of the ceramic is gradually decreased [11, 12].

Wang et al. [11] found that the intensity attenuation curves of ceramic materials can be classified into several distinct types. As shown in Fig. 4, as the thermal shocks increase, the residual strength can either:

(i) remain unchanged (curve $A$ );

(ii) have a linear decreasing trend (curve $B$ );

(iii) initially decrease and then remain unchanged at a certain value (curve $C$ );

(iv) slowly decrease (curve $D$ );

(v) exhibit a decreased acceleration (curve $E$ ).

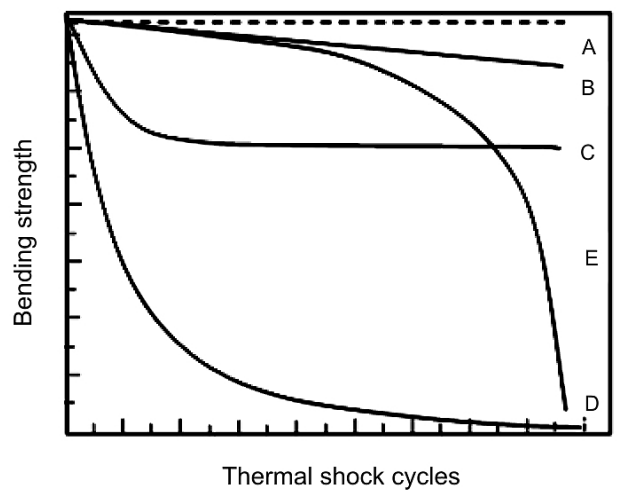

Fig. 4. Different types of damage curve.

All of the above curves can be described by Eq. (2):

$$
-\frac{\partial \sigma_{f}(N)}{\partial N}=a\left[\sigma_{f}(N)\right]^{1-m}
$$

The formula can be converted into

$$
\sigma_{f}^{m}(0)-\sigma_{f}^{m}(N)=m a N
$$

where $\sigma_{f}(0)$ is the original strength, $N$ is the number of thermal shocks, $\sigma_{f}(N)$ is the strength after $N$ shocks, and parameters $m$ and $a$ are related to materials and thermal shock conditions.

2.2. Life Calculation of Oxidation Bed. A fatigue equation for mullite ceramic was formulated based on the intensity attenuation equations and the thermal fatigue experiment data. From the resulting equation, the figure life of oxidation beds can be predicted by combining the equation with the oxidation bed's maximum thermal stress, which is obtained by numerical simulation.

According to the results of numerical simulation of oxidation beds, the temperature difference is normally about $240^{\circ} \mathrm{C}$ at a steady working state and the maximum stress is 22.4 MPa. To predict the thermal fatigue life of oxidation bed, the thermal fatigue life 
between $\Delta T=200$ and $300^{\circ} \mathrm{C}$ was calculated to estimate the life span of a ceramic bed at $\Delta T=240^{\circ} \mathrm{C}$.

2.2.1. The Establishment of the Thermal Fatigue Equation. Based on the intensity attenuation equation and the experimental data, the fatigue life equations of mullite $\Delta T=200$ and $300^{\circ} \mathrm{C}$ were developed. The related experimental data is shown in Tables 3 and 4 .

$\mathrm{T}$ a b 1 e 3

Fatigue Experiment Data at $\Delta T=200^{\circ} \mathrm{C}$

\begin{tabular}{|l|c|c|c|c|c|c|c||}
\hline \hline Numbers of thermal shock & 0 & 1 & 5 & 10 & 20 & 30 & 40 \\
\hline Residual intensity (MPa) & 25.36 & 24.95 & 24.68 & 24.33 & 23.92 & 23.53 & 23.03 \\
\hline
\end{tabular}

$\mathrm{T}$ a b 1 e 4

Fatigue Experiment Data at $\Delta T=300^{\circ} \mathrm{C}$

\begin{tabular}{|l|c|c|c|c|c|c|c||}
\hline Numbers of thermal shock & 0 & 1 & 5 & 10 & 20 & 30 & 40 \\
\hline Residual intensity $(\mathrm{MPa})$ & 25.36 & 24.97 & 24.60 & 24.16 & 23.60 & 23.23 & 22.70 \\
\hline
\end{tabular}

According to Eq. (2) and Tables 3 and 4, the thermal fatigue equation at $\Delta T=200$ and $300^{\circ} \mathrm{C}$ can be obtained using an lsqcurvefit function (Matlab). They resulting equations are

$$
\begin{gathered}
\sigma_{f}^{8.1207}(0)-\sigma_{f}^{8.1207}(N)=109760 \cdot 8.1207 \cdot N \quad\left(\Delta T=200^{\circ} \mathrm{C}\right), \\
\sigma_{f}^{7.325}(0)-\sigma_{f}^{7.325}(N)=105630 \cdot 7.325 \cdot N \quad\left(\Delta T=300^{\circ} \mathrm{C}\right) .
\end{gathered}
$$

The graphs of Eqs. (4) and (5) are shown in Figs. 5 and 6.

It can be seen from Figs. 5 and 6 that both the curve for $\Delta T=200^{\circ} \mathrm{C}$ and the curve for $\Delta T=300^{\circ} \mathrm{C}$ belong to curve type $E$. With $E$ type curves, after the number of thermal shocks reaches a certain value, the residual strength decreases at an accelerated rate as the number of thermal shocks continues to increase. Therefore, the calculated life of the material $\left[\sigma_{f}(N)=0\right]$ at $\Delta T=200$ and $300^{\circ} \mathrm{C}$ is 287,207 and 25,224 cycles, respectively.

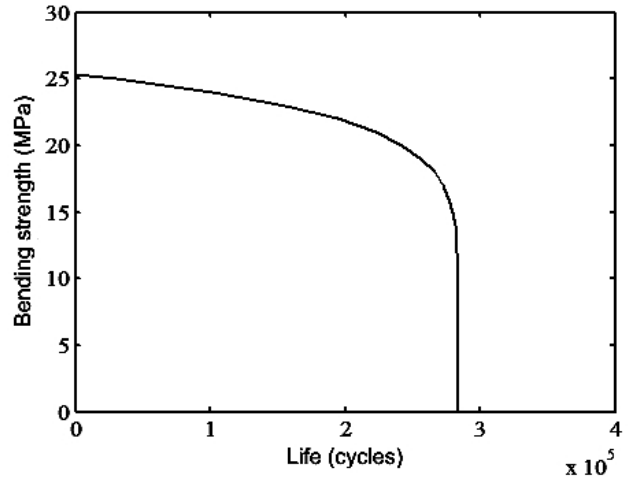

Fig. 5. Damage curve at $\Delta T=200^{\circ} \mathrm{C}$.

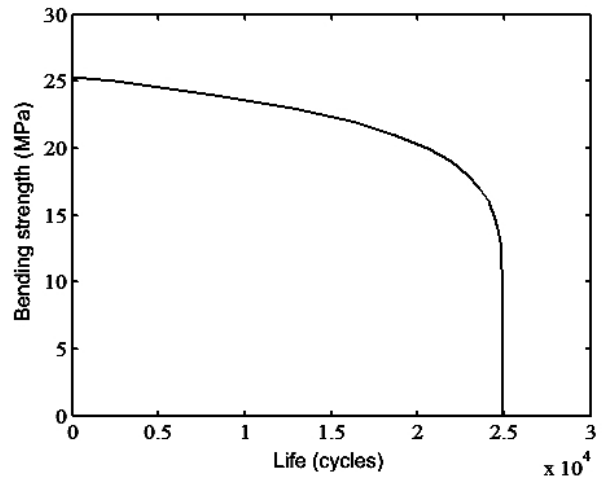

Fig. 6. Damage curve at $\Delta T=300^{\circ} \mathrm{C}$.

2.2.2. Fatigue Life Estimation of Regenerative Oxidation Beds. The maximum stress of oxidation beds is $22.4 \mathrm{MPa}$. This can be plugged into Eqs. (4) and (5) in order to obtain 
the oxidation bed's life. The resulting life is 183,711 cycles at $\Delta T=200^{\circ} \mathrm{C}$ and 15,178 cycles at $\Delta T=300^{\circ} \mathrm{C}$.

2.3. Validation and Analysis. In numerical simulation of oxidation beds, both the heat released time and heat storage time is $60 \mathrm{~s}$. This means that the oxidation bed was shocked once every 2 minutes. If the regenerative oxidation bed worked continuously, the service life of oxidation bed would be between 0.702 and 8 months. According to the statistics of various kinds of engineering applications, the service life of the honeycomb ceramic oxidation bed is generally no less than $2-3$ months. Sometimes, oxidation beds last as long as 6-12 months. For example, mullite honeycomb ceramic is used in steel rolling heating furnaces to recover flue gas heat. At low temperatures, the service life of a heating furnace can reach six months. At high temperatures, the service life of the heating furnace is no more than 3 months. Therefore, the predicted results are reasonable.

In practical applications, the actual service life of a given oxidation bed will be influenced by various conditions. For the oxidation beds that are used in VAM thermal flow-reversal reactors, if the service life of the oxidation bed is too short, running costs of the thermal flow-reversal reactor will be greatly increased. In order to effectively extend the service life of the oxidation bed, the gas flow reversing cycle has been widely extended.

\section{Con clusions}

1. On the whole, the bending strength of mullite ceramics had a decreasing trend as thermal shocks were increased. The bending strength at different temperature differences had different trends: at $\Delta T=400$ and $500^{\circ} \mathrm{C}$, the bending strength decreased more quickly than it did at $\Delta T=200$ and $300^{\circ} \mathrm{C}$; at $\Delta T=600,700$, and $800^{\circ} \mathrm{C}$, as subcritical extension of cracks occurred, the bending strength declined initially, and after reaching a certain value it remained unchanged for a while and then declined again.

2. Based on intensity attenuation theory and thermal fatigue data, the thermal fatigue equations at $\Delta T=200$ and $300^{\circ} \mathrm{C}$ were established. The fatigue life of mullite ceramic at $\Delta T=200$ and $300^{\circ} \mathrm{C}$ is $2.8 \cdot 10^{5}$ and $2.5 \cdot 10^{4}$ cycles, respectively.

3. According to the results of the simulation, the thermal fatigue life of an oxidation bed is 1-8 months. This result is consistent with observations of oxidation beds that are subjected to actual working conditions. These results illustrated that the prediction method is reasonable.

Acknowledgments. This work is supported by a grant from the National High Technology Research and Development Program of China (863 Program) (2009AA063202) and the Shandong Province Natural Science Fund (ZR2013EEQ008, ZR2011EL017).

1. Y. P. Cheng, L. Wang, and X. L. Zhang, "Environmental impact of coal mine methane emissions and responding strategies in China," Int. J. Greenhouse Gas Control, 5, 157-166 (2011).

2. K. Warmuzinski, "Harnessing methane emissions from coal mining," Process Safety Environ. Protect., 86, 315-320 (2008).

3. K. Gosiewski, Y. Sh. Matros, K. Warmuzinski, et al., "Homogeneous vs. catalytic combustion of lean methane-air mixtures in reverse-flow reactors," Chem. Eng. Sci., 63, 5010-5019 (2008).

4. Y. X. Yuan, "Emission and utilization of coal mine VAM," Energy and Energy Conservation, 11, 55-57 (2012).

5. I. Karakurt, G. Aydin, and K. Aydiner, "Mine ventilation air methane as a sustainable energy source," Renewable and Sustainable Energy Reviews, 1, 1042-1049 (2011). 
6. P. F. Wang, T. Feng, and X. L. Hao, "One-dimensional numerical simulation of thermal reverse-flow oxidation of ventilation air methane in coal mine," J. Min. Safety Eng., 29, 435-439 (2012).

7. M. M. Mao, Y. Q. Liu, B. Zheng, et al., "Investigation of temperature distribution uniformity in a preheating catalytic oxidation bed," J. China Coal Soc., 40, 109-114 (2015).

8. P. Y. Sang, L. Chen, X. N. Zhang, et al., "Mine diluted gas low concentration gas oxidation numerical simulation research," Coal Chem. Industry, 37, 24-27 (2014).

9. P. F. Wang, T. Feng, S. L. Li, et al., "Resistance characteristics of thermal reverse flow oxidation bed for coal mine ventilation air methane," Natural Gas Industry, 32, 73-77 (2012).

10. Z. Z. Jin, Y. W. Bao, and X. M. Yue, "High temperature fatigue strength degradation theory for structural ceramics," High Technol. Lett., 12, 31-36 (1994).

11. J. Z. Wang, Z. Z. Jin, H. Wang, et al., "Research on thermal shock fatigue of refractories," J. Chinese Ceram. Soc., 28, 91-94 (2000).

12. Z. X. Li, X. S. Wang, and Z. G. Wang, "Analysis on the devastate mechanics of ceramic regenerative materials," Metallurgy and Energy, 22, 43-45 (2003).

Received 03. 08. 2015 